\title{
O acervo do Museu de Arte Moderna do Rio de Janeiro: a produção experimental e Cildo Meireles ${ }^{1}$
}

\section{Daniele Machado² e Stefania Paiva ${ }^{3}$}

Resumo: O incêndio de 1978 interrompeu a marcante relação entre o MAM Rio e as vanguardas, deixando uma lacuna histórica na instituição. Entre as iniciativas de reparação por meio do acervo está um conjunto de aquisições realizadas em 2001, incluindo Marulho, de Cildo Meireles. Como esta foi gerida a partir de então?

Palavras-chave: Museu de Arte Moderna do Rio de Janeiro; Gestão de acervo; Arte experimental; Cildo Meireles.

\section{The Museum of Modern Art of Rio de Janeiro Collection: experimental production and Cildo Meireles}

\begin{abstract}
The fire in 1978 interrupted a remarkable relationship between MAM Rio and the avant-garde, leaving a historical gap in the institution. Among the initiatives to redress this through the collection is a set of acquisitions that was made in 2001, which includes Marulho, by Cildo Meireles: how has it been managed since then?
\end{abstract}

Keywords: Museum of Modern Art of Rio de Janeiro; Collection management; Experimental Art; Cildo Meireles.

1 Este artigo foi realizado no âmbito do projeto "História da Arte Global" do Programa de Pós-Graduação em História da Arte da Universidade do Estado do Rio de Janeiro, que conta com apoio financeiro da Fundação de Amparo à Pesquisa do Estado do Rio de Janeiro (Edital n. 12/2019).

2 Doutoranda em História da Arte pelo Programa de Pós-graduação em História da Arte da Universidade do Estado do Rio de Janeiro. Mestra em Estudos Contemporâneos das Artes pelo Programa de Pós-Graduação em Estudos Contemporâneos das Artes da Universidade Federal Fluminense. Graduada em História da Arte pela Universidade Federal do Rio de Janeiro. Bolsista da Fundação de Amparo à Pesquisa do Estado do Rio de Janeiro. Discente da Universidade do Estado do Rio de Janeiro - São Francisco Xavier, 524 - Maracanã, Rio de Janeiro - RJ, 20943-000. E-mail: machadodani08@gmail.com. ORCID: https://orcid.org/0000-0002-0294-0472. Lattes iD: http://lattes.cnpq. br/6323087753244561. Rio de Janeiro, Brasil.

3 Doutoranda em História da Arte pelo Programa de Pós-Graduação da Universidade do Estado do Rio de Janeiro. Mestra em Memória de Acervos pelo Programa de Pós-Graduação em Memória e Acervos da Fundação Casa de Rui Barbosa. Graduada em Comunicação Social, Jornalismo, pela Rede de Ensino Doctum, Caratinga, Minas Gerais. Discente da Universidade do Estado do Rio de Janeiro - São Francisco Xavier, 524 - Maracanã, Rio de Janeiro - RJ, 20943-000. E-mail: tamanduaproducao@gmail.com. ORCID: https://orcid.org/0000-0002-9880-0051. Lattes ID: http://lattes. cnpq.br/6480442664973902. Rio de Janeiro, Brasil. 
O presente artigo e O Museu de Arte Moderna do Rio de Janeiro, Maria Martins e a institucionalização da arte moderna no Brasil foram desenvolvidos por meio de uma investigação coletiva que reuniu quatro pesquisas sobre o acervo do Museu de Arte Moderna do Rio de Janeiro (MAM Rio).

O texto elaborado por Emmanuele Russel e Gabriela Caspary analisa a primeira década de existência do museu e a atuação de Maria Martins nessa parte da trajetória da instituição por meio de diversos documentos institucionais, apresentando dados que circulam pouco e permitem conhecer melhor a história inicial do MAM Rio.

Já este artigo se concentra no exame de um conjunto de aquisições realizadas pelo MAM Rio, em 2001, intitulado Aquisições Essenciais, que apresenta artistas relacionados aos episódios mais valorizados pela instituição em sua própria história. Esta ação vai ao encontro da avaliação de uma série de profissionais do campo artístico, mais ou menos relacionados ao museu, que foram entrevistados em 1980 sobre a história do MAM Rio. Este se firmou no imaginário comum como um museu que colaborava com a produção artística antes da exibição, que atuava junto às vanguardas de cada época e que, neste sentido, deixou de existir

Figura 1 Cildo Meireles Marulho, 1991/1997 Instalação, Rampa de madeira, livros e trilha sonora, $18 \times 20 \times 7 \mathrm{~m}$ Foto: Felipe Braga. Coleção do artista

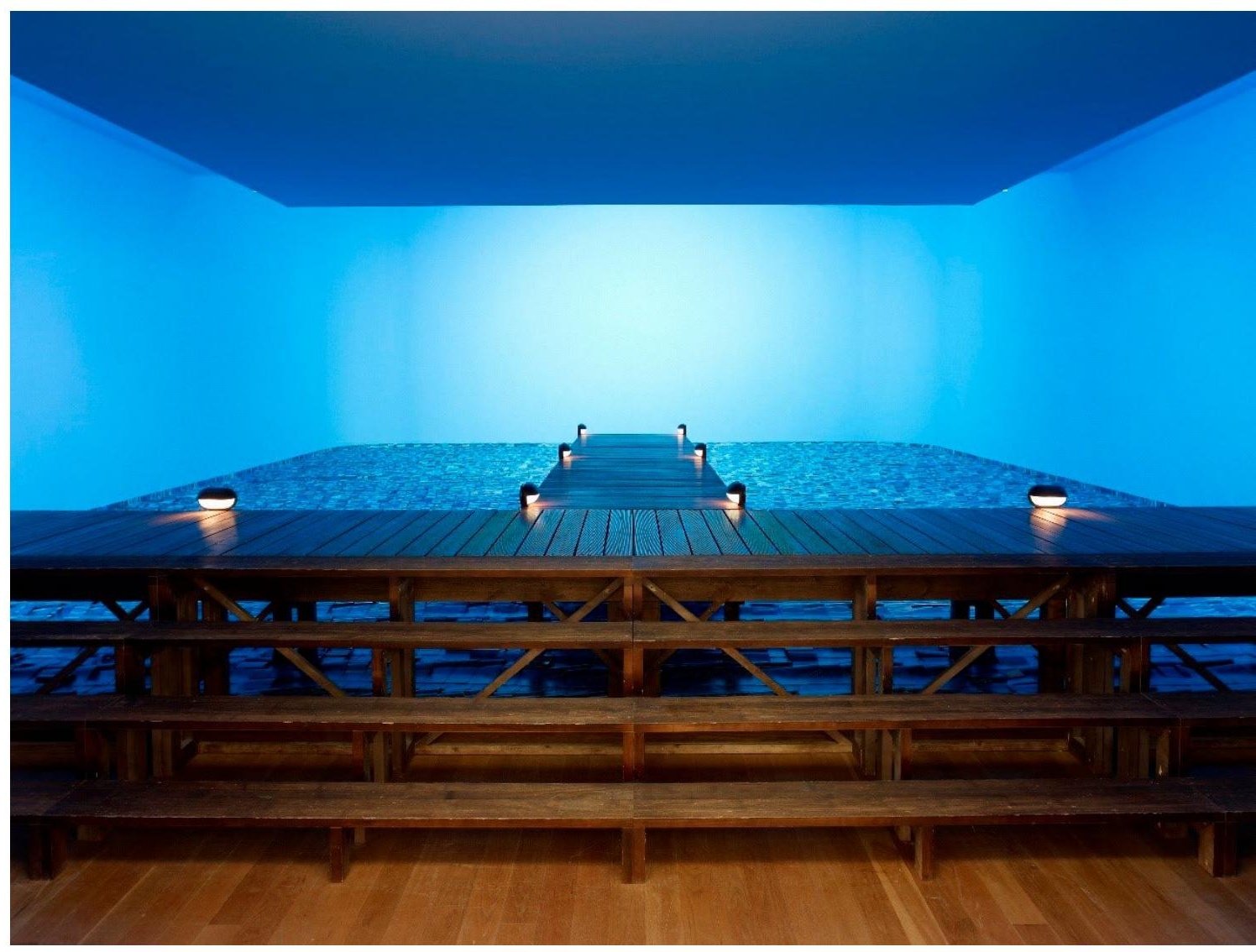


após o incêndio ocorrido em 1978. Devido à proximidade temporal, com frequência, a vanguarda em evidência, por parte dos entrevistados e dos entrevistadores, é a produção chamada "experimental".

As entrevistas foram realizadas no âmbito do projeto de pesquisa para a elaboração do Dossiê MAM, em 1980, iniciativa do Projeto Arte Contemporânea Brasileira (Projeto $A B C$ ) da Fundação Nacional de Artes (Funarte). O MAM Rio foi tomado como caso de estudo para investigar as relações entre arte e instituição no país. O projeto, porém, contou com diversas interrupções e, por fim, não foi publicado. Aqui são apresentadas apenas as entrevistas disponíveis no Centro de Documentação da Funarte. Alfredo Herkenhoff, Deborah Danowski, Elisa Byington e Geraldo Carneiro entrevistaram: dois ex-diretores executivos do MAM Rio, Heloisa Lustosa e Maurício Roberto; o ex-diretor da Cinemateca do museu, Cosme Alves Netto; três críticos de arte, Ferreira Gullar, Ronaldo Brito e Wilson Coutinho; o artista Adriano de Aquino.

Os relatos têm em comum a referência ao encerramento do "museu-laboratório", o museu que colaborava com o artista para além da exibição, que, na ocasião dos anos prévios ao incêndio, tinha como ápice a produção dita "experimental". Com o intuito de compreender como a obra de artistas valorizados por fazerem parte da trajetória experimental do museu foi gerida após sua aquisição, o presente artigo aborda, na atualidade, uma delas: Marulho, de Cildo Meireles. A admissão do núcleo intitulado como "experimental", pelo curador do museu à época, Fernando Cocchiarale, e do qual Marulho faz parte, tratar-se-ia de um esforço institucional de datar essa produção em seu acervo e cumprir com o dever histórico de recuperar a estimada programação da Área Experimental do museu, encerrada pelo incêndio. Tais imbricações serão analisadas aqui.

\section{Vanguarda, Experimental, Laboratório}

"O Museu de Arte Moderna do Rio de Janeiro é voltado às vanguardas e à experimentação nas artes, cinema e cultura." (MAM Rio, 2021) Esta frase inicia a definição institucional do MAM Rio, na página Sobre, de seu sítio eletrônico, hoje, ano de 2021. O museu carioca construiu a imagem de instituição aberta à vanguarda, à arte contemporânea de cada época, ancorado em parte da história que construiu em suas três primeiras décadas de funcionamento, um período cristalizado e encerrado pelo incêndio ocorrido no Bloco de Exposições em 1978. 
No fim dos anos 1960, o museu já estava marcado pelo comprometimento com algumas vanguardas de cada época. Esse comprometimento ia além da exibição, o que era uma característica que o distinguia de outras instituições museológicas brasileiras. Na década anterior, a instituição havia ficado marcada pelo envolvimento com o Grupo Frente e o Neoconcreto e por uma programação de ensino que abrangia públicos diversos, tornando-se uma referência, na cidade do Rio de Janeiro, de ensino alternativo ao tradicional que era ofertado pela Escola Nacional de Belas Artes. ${ }^{1}$

O museu foi se tornando um espaço de encontro, como lembraram os artistas Wanda Pimentel e Antonio Manuel, respectivamente: "O MAM tinha uma cantina, e nós nos encontrávamos ali todos os dias. Ficávamos conversando, falando sobre nossos trabalhos".2 "O MAM era onde compartiIhávamos nossas experiências, falávamos sobre nossos trabalhos. Era um lugar de troca e de reflexão. Todos se reuniam ali". ${ }^{3}$

Nesse período, o Brasil vivia os primeiros anos da ditadura civil-militar de 1964. A articulação museu-vanguarda dos anos de 1950 foi acentuada a partir do contexto cultural que se impunha com a nova conjuntura política. Conforme avalia Fernanda Pequeno (2018), no ano emblemático de 1968, o museu não realizou nenhuma exposição de envergadura, em contraste com os anos anteriores. Em contrapartida, o "programa" museu como lugar de encontro foi radicalizado e o vocabulário "experimental" começou a ser proliferado.

Em 1968, organizado pelo crítico de arte Frederico Morais, com patrocínio do jornal Diário de Notícias, foi realizado o evento Arte no Aterro: um mês de arte pública: uma programação pública de exposições e aulas no Parque do Flamengo, que fomentava a participação ativa dos visitantes. Com frequência, o evento é associado ao MAM Rio, que não colaborou na organização, como analisa Fernanda Pequeno. Ainda assim, a historiadora da arte avalia que o "evento pensava o lado de fora da instituição artística, propondo o Aterro do Flamengo como uma extensão do MAM Rio" (PEQUENO, 2018, p. 149).

1 Atual Escola de Belas Artes da Universidade Federal do Rio de Janeiro.

2 (informação verbal) PIMENTEL, Wanda. [Depoimento concedido a uma das autoras]. Rio de Janeiro (casa da artista), 29 set. 2017. (gravação em áudio - 1 h15 min.)

3 (informação verbal) MANUEL, Antonio. [Depoimento concedido a uma das autoras]. Rio de Janeiro (ateliê do artista), 12 set. 2017. (gravação em áudio - 1h25 min.) 
Para Pequeno, o evento se tornou uma referência na história da arte brasileira por apresentar a "instantaneidade ou a curta duração das propostas artísticas" e por ter buscado "uma aproximação com o público", características "potencialmente críticas à ordem estabelecida, tanto no sentido artístico quanto no institucional" (PEQUENO, 2018, p. 155). A pesquisadora ainda coloca o evento como antecessor de Domingos da Criação, também organizado por Morais, em 1971, no MAM Rio.

Para Fernanda Lopes, autora do livro Área Experimental: lugar, espaço e dimensão do experimental na arte brasileira dos anos 1970 (2013), não havia, neste período, uma definição consensual do que era o "experimental" no MAM Rio, o que poderia ser visto como uma estratégia:

significou manter essa possibilidade de escolha em aberto. Não restringir o "experimental" a uma única proposta artística, como o vídeo, a pintura, o ambiente, o desenho, ou qualquer outro suporte, trazia como desafio pensar o quanto de experimentação a pintura, o vídeo, o desenho, a escultura, a instalação etc. podiam ter. Não importa o suporte, ele teria que ser repensado criticamente (LOPES, 2013, p. 49).

Para a autora, tratava-se, ainda, de questionar os espaços artísticos, pressionando por sua ampliação e reinvenção. Lopes completa adicionando que, no caso da Área Experimental, as propostas artísticas eram apresentadas como projetos nos quais o risco era fundamental. Historicamente, a crítica de arte assinala que a percepção experimental encontrada na produção neoconcreta, associada à fenomenologia, à plurissensorialidade, à ludicidade, transforma-se com a violência social imposta pela ditadura, parecendo

se reconfigurar em trabalhos mais "agressivos", que traziam indagações não só sobre os limites das categorias e suportes artísticos, mas também sobre os termos a partir dos quais a sociedade e os sistemas de poder se estruturavam e funcionavam (LOPES, 2013, p. 51).

No ano seguinte ao Arte no Aterro, o MAM Rio foi palco do Salão da Bússola ${ }^{4}$, que trouxe à tona a produção de jovens artistas brasileiros, apresen-

4 O Salão da Bússola foi realizado com o objetivo de comemorar o quinto aniversário da empresa Aroldo Araújo Propaganda, sua patrocinadora. O tema da mostra foi escolhido por se tratar de ser instrumento fundamental para a "descoberta de novos caminhos, horizontes mais amplos para a humanidade", conforme encontra-se em Material impresso de divulgação do $1^{\circ}$ Salão da Bússola (1969). O Salão inovou ao permitir a submissão de trabalhos que não se enquadravam nas categorias artísticas tradicionais, tais como happenings e objetos. Isso colaborou para o envio de trabalhos inusitados, considerados, em sua maioria, "estranhos" e "um desafio à inteligência" pelo júri, conforme o artigo do Jornal do Brasil: Volume de trabalhos para Salão da Bússola no MAM desorienta até 
tando uma nova postura que aliava a produção de arte à crítica social e política, aprofundando as investigações da arte experimental e da relação artista-público. O grupo de artistas atuantes desde o final da década de 1960 foi chamado por Frederico Morais de "Geração Al-5". Diante de uma produção de arte inevitavelmente afetada pelo contexto político-social, o crítico escreve:

Na guerra convencional da arte, os participantes tinham posições bem definidas. Existiam artistas, críticos e espectadores. O crítico, por exemplo, julgava, ditava normas de bom comportamento, dizendo que isto era bom e aquilo ruim, isto válido, aquilo não, limitando regras de atuação, defendendo categorias e gêneros artísticos, os chamados valores plásticos e os específicos. Para tanto, estabelecia sanções e regras estéticas (éticas). Na guerrilha artística, porém, todos são guerrilheiros e tomam iniciativas. O artista, o público e o crítico mudam continuamente suas posições no acontecimento e o próprio artista pode ser vítima da emboscada tramada pelo espec$\operatorname{tador}^{5}$ (MORAIS, 1975, p. 30).

Entre os artistas selecionados para o Salão da Bússola, estavam: Cildo Meireles, Artur Barrio, Antonio Manuel, Carlos Vergara, Thereza Simões, Guilherme Magalhães Vaz, Luiz Alphonsus, Wanda Pimentel, Pedro Escosteguy, Anna Bella Geiger, Luciano Gusmão, Dilton Araújo, Lótus Lobo, Raimundo Colares e Antônio MMM. Cildo foi premiado em primeiro lugar, angariando $\mathrm{NCr} \$ 6.000,00$ e passagens aéreas para as cidades de Londres e de Nova York, com a obra Nowhere is my home (1969), um ambiente em madeira criado pelo artista, que integra a série Cantos.

Também em 1969, o crítico de arte Frederico Morais criou a Unidade Experimental no museu carioca, junto a Cildo Meireles, Guilherme Vaz e Luiz Alphonsus. Morais, na época, assinalou do que a proposta se tratava:

As atividades e realizações da UE [Unidade Experimental] terão em mira a codificação de novas linguagens que incluiriam formas de pensamento e de comunicação e informação através de todos os sentidos (tato, cheiro, audição etc.) numa exploração mais ampla da capacidade lúdica do homem, ou seja, de uma pesquisa interdisciplinar, em todos os campos sem qualquer limitação de ismos, cânones, salões ou escola (MORAIS, 1969).

promotores (1969). Igualmente, a quantidade de obras inscritas: mais de mil.

5 O texto foi publicado originalmente com o título Contra a arte afluente, pela Revista Vozes, em janeiro de 1970. 
O trecho acima pertence ao texto Um laboratório de Vanguarda, assinado por Frederico Morais no Diário de Notícias, em 1969. O artigo mencionava ainda a interdisciplinaridade como prevenção ao risco de se limitar a "ismos". Como toda saga vanguardista, ainda mais nesse caso, no qual a vanguarda está amparada por uma instituição, a assimilação e a categorização não demoraram a acontecer. A sequência experimental no MAM Rio teve a Área Experimental como seu último episódio e foi encerrada pelo incêndio de 1978. Em 1980, quando o Projeto ABC, da Funarte, iniciou o projeto, não concluído, do Dossiê MAM, a arte "experimental" estava estabelecida no discurso dos entrevistados para o projeto.

\section{Dossiê MAM}

No ano de 1980, o Projeto ABC, da Funarte, iniciou a produção do Dossiê MAM, com o objetivo de preencher uma lacuna histórica nos estudos das relações entre arte e instituição no Brasil, tendo o museu carioca como caso de estudo. $O$ dossiê não chegou a ser concluído nem publicado. Entre o material de pesquisa produzido, existe, no Centro de Documentação da Funarte, um conjunto de sete entrevistas que discutem, especialmente, o incêndio da instituição de 1978 e as gestões anteriores a esse evento.

Alfredo Herkenhoff, Deborah Danowski, Elisa Byington e Geraldo Carneiro entrevistaram figuras de distintos perfis de atuação no campo artístico: os ex-diretores executivos do MAM Rio, Maurício Roberto, arquiteto que dirigiu a instituição de 1967 a 1972, e Heloisa Lustosa, filósofa que atuou nesse cargo de 1972 a 1979; Cosme Alves Netto, que foi diretor da Cinemateca do museu entre 1965 e 1989.

Além dos três gestores, que influenciaram diretamente os rumos da instituição museológica, estão, entre os entrevistados, três críticos de arte: Ronaldo Brito, que atuou na gestão da programação do museu no período da direção de Lustosa; Ferreira Gullar, que atuou no Neoconcretismo, movimento que contou com grande apoio do MAM Rio; Wilson Coutinho, que se envolveu com a instituição em um projeto de criação de cursos que não obteve sucesso. Por fim, temos o artista Adriano de Aquino, ex-presidente da Associação Brasileira de Artistas Plásticos (ABAPP), que teve trabalhos destruídos no incêndio.

Ao avaliarmos o material, com o objetivo de compreender quais perdas materiais e simbólicas geradas pelo incêndio foram sentidas, é marcante a discrepância nas menções ao acervo e à programação. $\mathrm{O}$ acervo não tem destaque em 
nenhuma das sete entrevistas, apesar de ter sido o setor do museu mais afetado pelo incêndio. Já a programação aparece com frequência em todas as entrevistas, em especial, a que era voltada à arte experimental. Esta, não era associada ao acervo, mas tratada como oposição à ideia de uma coleção museológica.

$\mathrm{Na}$ entrevista do crítico e poeta Ferreira Gullar, o acervo não se torna assunto. Como integrante do antigo grupo Neoconcreto, foi questionado sobre como foi a assimilação dessas vanguardas pelo museu e respondeu:

Neste sentido, o Museu era aberto (...) o Museu abriu suas portas para o nosso movimento numa época em que ele era bastante combativo, as pessoas procuravam até ridicularizar (...) [sobre a primeira exposição Neoconcreta, 1959] o Museu prestigiou a exposição, abriu a exposição, abriu as portas, deu tudo o que pôde (...) O Museu neste sentido sempre desempenhou um papel de vanguarda, dentro das condições da época" (GULLAR, 1980, p. 4 - 5).

Apesar da defesa da interdisciplinaridade no museu estar presente em todas as entrevistas e nas propostas experimentais, a Cinemateca e o acervo cinematográfico do MAM Rio são abordados somente pelo ex-diretor da Cinemateca do museu. Quanto às perdas geradas pelo incêndio, Cosme Alves Netto foi assertivo ao distinguir duas forças atuantes na instituição:

\begin{abstract}
O museu que pegou fogo não foi o museu-proposta-cultural (...) porque realmente não é quadros, paredes, é aquele da expressão popular (...) O museu assusta (...) parece uma espécie de templo, onde só entra quem for iniciado. Então estava-se tentando exatamente quebrar isso (...) Por um lado fazendo com que esse povo entrasse dentro do museu. Por outro lado, fazendo com que o museu como projeto, como planificação, saísse e fosse para a praça. Essa experiência é que foi destruída (...) Acho que há dois museus, um foi destruído pelo fogo e outro foi destruído pelo medo dessa elite dirigente que não assumiu a continuidade de uma proposta (NETTO, 1980, p. $6-7)$.
\end{abstract}

Ainda que o MAM Rio seja uma instituição museológica, é marcante que todos os entrevistados compreendessem que a atividade fim do museu era a programação. A ex-diretora executiva do museu, Heloisa Lustosa, mencionou que $60 \%$ do orçamento da programação cultural do MAM Rio, antes do incêndio, era investido na Área Experimental, com a justificativa de que o projeto propiciava a continuidade da produção de jovens artistas, ainda não assimilados no circuito comercial.

Lustosa também abordou suas preocupações sobre a reconstrução do edifício após o incêndio, que representava, para ela, uma oportunidade para adequar a sede do MAM Rio às antigas lacunas: o acolhimento da produção experimental. É intrigante que, após um incêndio, a ex-diretora executiva da 
instituição não tenha mencionado que a reserva técnica também fosse uma antiga problemática da estrutura do edifício, o que pode ser compreendido em sua própria entrevista, quando avalia que a ausência de técnicos especializados nas demandas de um museu era um problema desde a sua fundação.

Niomar Moniz Sodré e Assis Chateaubriand, ambos fizeram uso da imprensa para promover as instituições que estavam empreendendo, com a diferença de que os Diários Associados investiram na construção do acervo do MASP, enquanto o Correio da Manhã, na construção do edifício do MAM RJ, "para felicidade do Rio de Janeiro (...) Ela pensou no invólucro, não no conteúdo” (ROBERTO, 1980, p. 2).

Outro ex-diretor executivo do museu que foi entrevistado, Maurício Roberto, era arquiteto, o que explica a percepção citada acima. Mas o trecho também corrobora a associação do MAM Rio mais à programação e ao fomento do encontro do que ao acervo. Maurício também menciona uma recente consciência história da instituição, que acabava, naquele momento, de deliberar a criação de um Instituto de Documentação do museu.

A oposição entre acervo e programação é acirrada nas entrevistas do artista Adriano de Aquino e dos críticos de arte Ronaldo Brito e Wilson Coutinho. Para Aquino, o museu não deveria ser um "depositório de obra", mas sim

uma coisa dinâmica, uma coisa que produz, ao mesmo tempo torna, transforma em patrimônio aquele tipo de coisa, aquele tipo de produção através de um patrimônio, através do seu registro ou pelo seu centro de documentação através do registro dos eventos (AQUINO, 1980, p. 30).

Os tipos de atividade descritas acima, para o artista, encaminhariam a instituição para deixar de ser um museu e se tornar um centro de arte. Sob um tom bastante incisivo, Aquino opõe o "museu vivo" ao "museu do acervo" e ao "museu didático". Para o artista, por meio da inclusão da classe artística na estrutura de deliberações do museu, este viria a se tornar um centro de produção contemporânea, "um território bastante específico sobre as questões da produção contemporânea". E esse museu desejado exigiria outros parâmetros de gestão. Nesse sentido, "a questão de competência do museu do passado fica muito relativizada" (AQUINO, 1980, p. 32).

No caso do crítico de arte Wilson Coutinho, o acervo teria a função de contemplar produções fora do espectro experimental,

trabalhos que não estão mais nesse espaço, trabalhos que já fecharam o círculo e que seriam trabalhos que se localizariam dentro do acervo do Museu. Não imagino Volpi agora fazendo arte experimental. Acho que ele deveria ter o acervo com o trabalho do Volpi (COUTINHO, 1980, p. 6). 
A principal função do museu deveria ser a promoção de condições materiais para a produção contemporânea, o que traria vitalidade para a instituição. Em suas palavras, o museu deixaria de

ser um mero depositário de obras - o acervo é importante. Sempre friso que essa pedagogia do olhar deve ser, deve estar lá institucionalizada. Mas essa dinâmica do museu é que deve ser pensada como elemento primordial (COUTINHO, 1980, p. 7).

Coutinho avalia que tal transformação implicaria também a definição da instituição, que deixaria de ser um museu para se tornar um "centro produtor" (COUTINHO, 1980, p. 7).

Ronaldo Brito presidiu a Comissão Cultural, junto a Roberto Pontual, chefe do departamento de exposições do museu, e à então diretora executiva Heloísa Lustosa, deliberando sobre a programação do MAM Rio nos anos prévios ao incêndio. $O$ crítico de arte, ao relatar essa atuação, reforçou que defendia expressamente a produção contemporânea, apesar de ter sido levado a tomar posição diante de outros tipos de produção.

Ao ser perguntado sobre o que haveria de mais marcante no MAM diante da recusa do mercado à produção fomentada pela Área Experimental, Brito respondeu que o museu se colocou

na posição de galeria, num certo sentido também na posição de espaço aberto a intervenções dos próprios artistas que teriam feito normal ou tradicionalmente exposições em outros espaços que não são o espaço marcado já pela consagração do museu. Então se caracterizou exatamente por esse espaço ambíguo, de ser ao mesmo tempo sacralizador e veiculador de produtos do mercado imediato, e ao mesmo tempo inovador na medida em que permitia que os artistas se associassem a isso (BRITO, 1980, p. 11).

Brito destoa de Aquino e Coutinho ao compreender que a reivindicação de artistas para participarem das decisões do museu não solucionaria suas fragilidades, mas, somente, uma "gerência técnica", orientada por uma "racionalidade técnica". Em comum entre os três, há a compreensão de que o foco do museu deveria estar na produção artística contemporânea brasileira que, frisa Ronaldo Brito, não seria somente a experimental.

Os dois críticos e o artista não associam a arte experimental com o acervo de obras, mas com o documental, o arquivo da instituição - um dado que pode ser compreendido por serem recentes, no início da década de 1980, no Brasil, as relações entre trabalhos de bases, suportes e materiais não tradicionais, mercado e acervo. A preocupação surge em termos de memória. 
Adriano de Aquino e Wilson Coutinho avaliam que os trabalhos contemporâneos - em suas palavras: experiências, eventos e acontecimentos - deveriam ser instituídos como patrimônio por meio do registro ou da produção documental. Brito vai além, afirmando que deveria ser construída uma "razão institucional contemporânea" para esse tipo de obra, que romperia com a tradição:

Não há mais por que haver Belas Artes entesourando aquelas coisas para uma eternidade que só existe na cabeça daquelas pessoas. O mundo de hoje não só não é eterno, como é o mundo do minuto (BRITO, 1980, p. 13).

\section{Núcleo Experimental: Marulho}

Gostaria de te ouvir falar sobre aquele momento no MAM, no final dos anos 60, início de 70, aquela efervescência. Por que o MAM foi um dos lugares que acolheu essas experimentações? Para você, por que o MAM? E por que isso foi tão potente? (GOGAN, 2017, p. 20)

Por que não o MAM? O que aconteceu foi que, com a evolução da vida política do Brasil, o arrocho da ditadura e a falta de liberdade acabaram estrangulando o MAM. Hoje, infelizmente, é um museu que não escancara como escancarava naquela época. Então, quando você pergunta por que o MAM? Porque era um lugar natural de um acontecimento dessa natureza. Um espaço amplo, vazio, bonito, capaz de aglomerar muita gente, um lugar onde se respirava liberdade, os melhores momentos, as meIhores coisas da arte brasileira se exibindo no MAM. O MAM era um organismo vivo, era um museu como deve ser um museu, e não um sarcófago onde ficam enterradas as obras-primas mumificadas eternamente. Então, é porque sim o MAM. A pergunta é por que não o MAM agora? Onde foi parar isso? Onde se perdeu? Eu sou um filho desse outro MAM (HADDAD, 2017, p. 20).

A recente publicação Domingos da criação: uma coleção poética do experimental em arte e educação (2017), da pesquisadora Jessica Gogan, com a colaboração de Frederico Morais, investiga este célebre evento do MAM Rio e a atmosfera de progressão da instauração do "programa experimental" no museu. Os trechos citados acima, que integram a entrevista de Gogan com o ator Amir Haddad, permitem constatar que a vinculação da história do museu com as vanguardas ainda se mantém no imaginário do campo cultural.

Lugar historicamente privilegiado da vanguarda e do experimentalismo no país, o Museu de Arte Moderna do Rio de Janeiro viu nascer parte considerável de nossos movimentos estéticos e lançou muitos de nossos artistas mais importantes. Do Grupo Frente (1954), formado a partir da primeira turma de adultos de Ivan Serpa no MAM ao Neoconcretismo (1959); do Atelier de Gravura (1959) à Nova Objetividade Brasileira (1967), passando pelas Opinião 65 e 66; das mostras Resumo JB (1964- 
1972), aos Salões de Verão (1969-1974); dos Domingos da Criação (1971) à Área Experimental (1975-1976), até o trágico incêndio de 1978, foram incontáveis os eventos e os artistas que pelo MAM passaram, ou nele tiveram uma referência fundamental para o florescimento de suas obras. Entretanto, seja pela destruição provocada pelo fogo, seja pela falta de recursos específicos para a aquisição de obras, sua coleção, a despeito dos esforços até agora feitos, ainda não refletem a história de ponta da arte brasileira moderna e contemporânea cujo berço privilegiado sempre foi o próprio museu (COCCHIARALE, 2001).

Em 2001, com patrocínio da Petrobras, o MAM Rio desenvolveu o projeto Aquisições Essenciais, com o objetivo de incorporar ao seu acervo um conjunto de 16 obras dos artistas Cildo Meireles, Antonio Manuel, Artur Barrio, Carlos Zilio, Décio Vieira, Hélio Oiticica, Ivan Serpa e Waltércio Caldas. O trecho citado acima pertence ao texto do curador do museu na época, Fernando Cocchiarale, para a exposição que apresentou as novas obras do acervo da instituição para o público.

As palavras do curador denotam a preocupação em fortalecer o caráter histórico da instituição e sua relação com a produção dos principais artistas brasileiros. Passadas mais de duas décadas desde o incêndio, este ainda se mantinha compreendido institucionalmente como uma interrupção, seja do acervo consumido pelas chamas, seja da programação, especialmente a experimental, que não chegou a ser inserida no acervo antes de 1978.

O programa de novas aquisições perpassa a relação do MAM Rio com as vanguardas de cada época, o que tornou a instituição uma referência obrigatória nos estudos sobre essas produções na história da arte brasileira. Tratou-se do início do comprometimento da instituição com o dever histórico de recompor as lacunas deixadas pelo incêndio. Tal preocupação está expressa no destaque dado à produção dos artistas que integraram estes importantes movimentos na composição do acervo:

Procuramos reforçar dois períodos fundamentais da arte brasileira em nossa coleção: O Grupo Frente, o Neoconcretismo (Décio Vieira, Hélio Oiticica e Ivan Serpa) e o experimentalismo (Antonio Manuel, Artur Barrio, Carlos Zilio, Cildo Meireles e Waltércio Caldas) (COCCHIARALE, 2001).

Contudo, há fragilidades que devem ser evidenciadas na articulação das aquisições com o discurso que as justificava. Ao mesmo tempo em que as aquisições pareciam tentar preencher uma lacuna histórica, no caso do citado experimentalismo, nota-se que a maioria das obras incorporadas ao acervo correspondem a produções recentes desses artistas e, portanto, não traduzem a fase em que eles estavam inseridos no contexto do MAM Rio. Por exemplo, Fantasma, de Antonio Manuel, é de 1994; a pintura Sem 
Título, de Carlos Zilio, é de 1999; a instalação Ping-Ping, de Waltércio Caldas, é de 1980. A instalação Marulho, de Cildo Meireles, é de 1991.

A obra de Antonio Manuel, Fantasma, é uma instalação cujo título alude a uma fotografia de um sobrevivente do massacre de Vigário Geral, que, após ser revelado pela imprensa, "precisou esconder-se, perdendo sua identidade, transformando-se em um fantasma ${ }^{6 "}$. O trabalho foi apresentado, pela primeira vez, no Fórum de Artes Plásticas de Brasília, em 1994. No ano seguinte, o artista montou uma versão expandida do trabalho a convite do Instituto Brasil-Estados Unidos (IBEU).

A instalação é constituída de cerca de novecentos pedaços de madeira queimada presos em fios atados em uma grade imperceptível. Os pedaços irregulares de carvão ficam aparentemente flutuando em alturas variáveis. Do outro lado, estimulando o visitante a atravessar a barreira, há a fotografia de uma pessoa com a cabeça encoberta por um pano branco e rodeada de microfones de equipes de reportagem, iluminada por lanternas suspensas. Para alcançar a imagem, o visitante passa por esse espaço tortuoso, desviando-se dos carvões, que sugerem uma forma individual de deslocamento no trajeto.

A instalação Ping-Ping, de Waltércio Caldas, foi realizada na Galeria Saramenha, no Rio de Janeiro, em 1980. A exposição foi acompanhada por um catálogo que apresentava um ensaio gráfico e um poema, ambos de autoria do próprio artista. Ping-Ping é uma das primeiras instalações de Waltércio Caldas, cuja produção se concentrava até então no trabalho em outros suportes como desenhos, objetos e esculturas, caixas e livros.

A obra apresenta um jogo de ping-pong em suspensão, cuja mesa fica pendurada em posição horizontal na parede e, diante dela, estão suspensos no ar a bola, uma rede com um furo circular, uma raquete com um furo idêntico e um par de óculos para pessoa cega, todo de plástico preto, sem lentes. A cena do jogo congelado parece torcer o espaço a partir da posição dos objetos que flutuam diante do olhar.

De Cildo Meireles, foi adquirida a instalação Marulho, de 1991, composta por madeira, tecidos, livros e som, medindo aproximadamente $347 \mathrm{x}$ $1.350 \times 2.300 \mathrm{~cm}$. Trata-se de um quebra-mar de madeira, uma espécie 
de deque, que dá para um chão coberto de livros abertos de tamanhos diferentes, nos quais se vê imagens de mar. Segundo o artista: "um mar de água seca" (MEIRELES, 2021, p.10). Há uma faixa sonora com uma montagem a partir da palavra "água", que é pronunciada em oitenta idiomas diferentes.

Cildo Meireles concebe suas instalações em três versões. No caso de MaruIho, criada em 1991 e montada pela primeira vez seis anos mais tarde, na Bienal de Joanesburgo, em 1997, o trio está distribuído entre os acervos do próprio artista, do MAM Rio e do Fundo Nacional de Arte Contemporânea - coleção pertencente ao Estado francês. A obra é acompanhada de um projeto que consiste em um mapa detalhado com todas as instruções para montagem. Mesmo que suas partes fiquem degradadas, não é necessário grande empenho para a restauração, pois o projeto pode ser refeito.

A instalação de Cildo Meireles esteve presente no circuito internacional de arte, mas não foi a versão pertencente ao MAM Rio que circulou. Em 2013, a obra esteve entre os destaques da exposição Cildo Meireles - Instalações, exibida no Museo Nacional Centro de Arte Reina Sofía, na Espanha, e no Museu de Arte Contemporânea de Serralves, em Portugal. No ano seguinte, o trabalho foi apresentado em uma exposição homônima na Fundação Pirelli Hangar Bicocca, na Espanha.

No caso do MAM Rio, desde a aquisição, há 20 anos, a obra Marulho foi apresentada em duas ocasiões: na exposição Aquisições Essenciais, no mesmo ano de sua incorporação ao acervo, e na mostra Em Polvorosa (2016/2017), ambas sob a curadoria de Cocchiarale.

A exposição Em Polvorosa teve Marulho como um de seus destaques. Foi uma mostra coletiva composta pelas obras de três coleções guardadas no museu (MAM Rio, Gilberto Chateaubriand e Joaquim Paiva). A curadoria privilegiou o acervo próprio, exibindo obras de mais de 100 artistas ocupando todo o segundo andar do museu. Em entrevista para o Jornal do Brasil, Cocchiarale destacou obras de artistas consagrados nacional e internacionalmente, como Pollock, Lygia Clark, Calder, Lucio Fontana, e salientou que também desejava distinguir artistas "muito conhecidos, mas pouco mostrados", como Anita Malfatti. (COCCHIARALE, 2001)

Por meio da política de empréstimo de obras para outras instituições, $\mathrm{Ma}$ rulho foi ainda exibida, em 2006, no Museu de Arte Contemporânea do Ceará e no Museu Vale do Rio Doce, no Espírito Santo. No ano seguinte, foi apresentada na $6^{a}$ Bienal do Mercosul, no Rio Grande do Sul. 
Cildo Meireles é um artista central na história da arte brasileira, com reconhecimento internacional. Hoje, no país, o Instituto Inhotim, em Minas Gerais, é a única instituição que oferece acesso permanente à sua obra. O esforço logístico e financeiro do MAM Rio em identificar e preencher algumas das lacunas históricas de seu acervo por meio do programa Aquisições Essenciais, ainda não pode ser compreendido como tendo sucesso, a exemplo de Marulho. Ao longo de 20 anos, o público direto, os cariocas, e os turistas que não visitaram o MAM Rio em 2001 ou em 2016 e 2017 não puderam conhecer a obra.

Em comparação, as obras de Antonio Manuel e Waltercio Caldas, além de terem sido exibidas no MAM Rio, nas mostras Aquisições Essenciais e Em Polvorosa, contabilizam apenas mais uma apresentação. Fantasma integrou a individual de Antonio, realizada na instituição, entre 2013 e 2014, e Ping-Ping, a coletiva MAM 60 anos - Formação da coleção, que ocorreu entre 2008 e 2009.

O reconhecimento internacional da obra de Cildo Meireles pode ser evidenciado com a instalação Babel, de 1992, que é exibida de forma permanente na Tate, em Londres. ${ }^{7}$ Em 2013, o trabalho foi adquirido pela instituição britânica (com a assistência do Comitê de Aquisições da América Latina e da Coleção D. Daskalopoulos) após um meticuloso levantamento da equipe de pesquisa da Tate Modern: "Eles chegaram ao ateliê com um dossiê completo, sabiam tudo sobre o trabalho, tinham informações que nem mesmo eu tinha arquivado" (MEIRELES, 2021, p.12).

O artista ainda conta que começou a elaborar Babel, em 1991, quando observava todos os diferentes tipos de rádios que eram vendidos na Canal Street, mas lembra que a obra também está ligada às suas memórias.

Quando criança, costumava ouvir rádio no escuro. Quando eu andava pelas ruas do Rio e via pessoas paradas, segurando livros, imaginava todos aqueles livros com imagem de água, e aí comecei uma peça chamada Marulho, que tem livros no chão e triIha sonora de vozes dizendo 'água', tudo em diferentes idiomas. Eureka/Blindhotland também tem fontes diferentes. Claro que tem a ver com o Buraco Negro, estrelas e coisas assim, mas também com literatura. Uma influência importante é The Metamorphosis, de Kafka, a história de um cara, que era muito regular, que sempre acordava alguns segundos antes do alarme tocar e ia ao banheiro. Um dia, ele acordou, e não era o horário habitual, era uma hora antes, e ele começou a ouvir sons, quando percebeu que os sons vinham daquele bicho que estava debaixo da cama dele e ele não sabia o que fazer com essa coisa de animal. E no final ele vai trabalhar e o Bug vai

7 Ver: https://www.tate.org.uk/art/artworks/meireles-babel-t14041 
Figura 2

Cildo Meireles

Babel, 2001 - 2006

Instalação, Estrutura

metálica e rádios,

$500 \mathrm{~cm} \times 260 \mathrm{~cm}$

Sophie Mutterer.

Collection Tate

Modern London

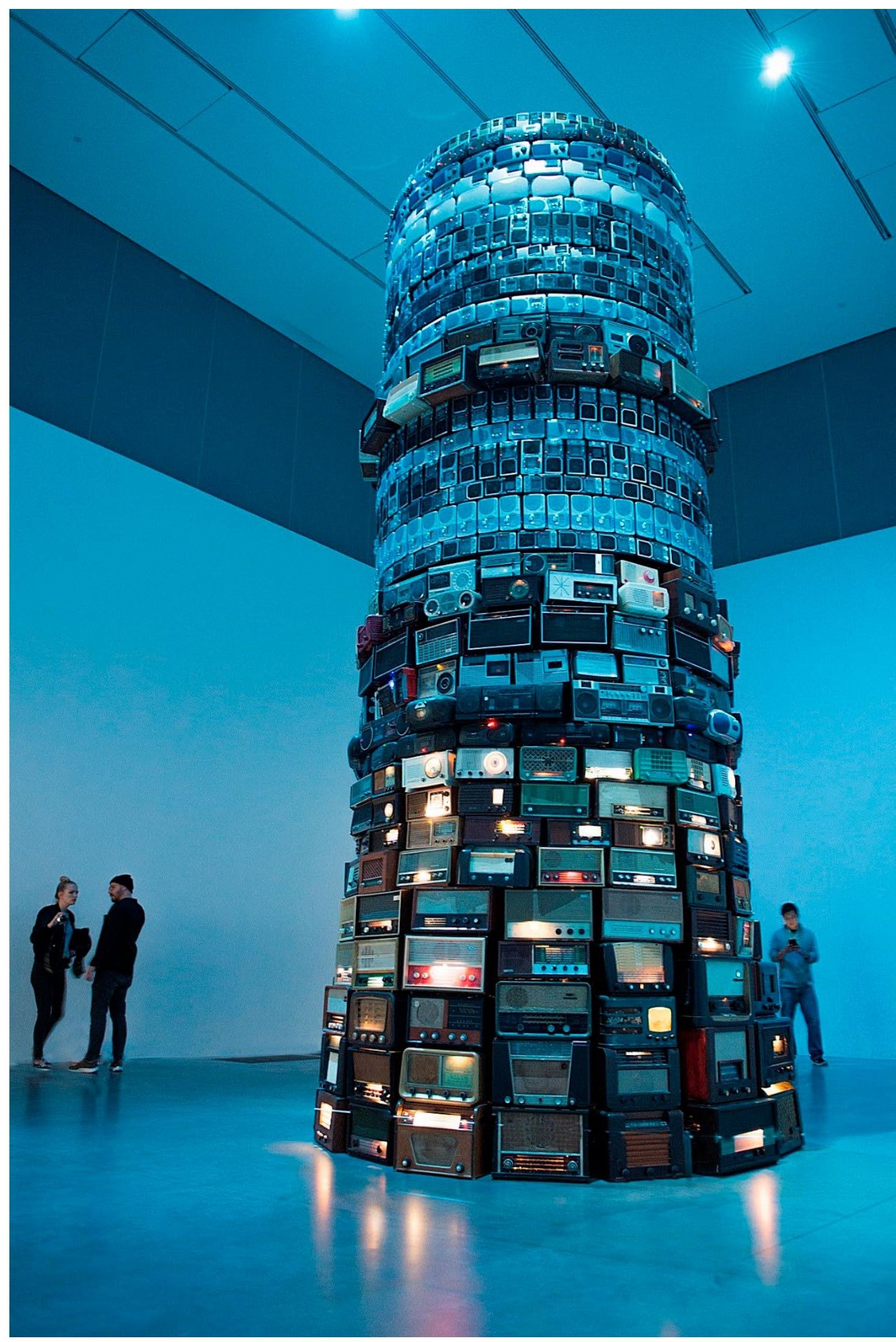


atrás dele. Também fui muito influenciado por contos, como o de Jorge Luis Borges que acontece em uma espécie de Brasil, onde alguém carregava algo tão pesado que quase não conseguia pegar com as mãos. Muitos dos meus trabalhos vêm de situações, como andar na rua, e, no meu caso, a inspiração urbana é muito importante. Camelô, por exemplo, vem de uma experiência pelas ruas do Rio de Janeiro com meu pai. Tem também uma história que ele costumava me contar, tornou-se Ku Kka Ka Kka. Então, cada obra tem uma espécie de pequena biografia (MEIRELES, 2021, p.16).

As problemáticas que envolvem a exibição do acervo do MAM Rio não são recentes, sendo identificadas há décadas pela crítica brasileira. Em 1975, o crítico de arte Francisco Bittencourt publicou o texto $O$ acervo do MAM, no qual ele refletia sobre a exposição Arte Brasileira - Acervo MAM, realizada naquele ano. Entre problemas financeiros e de gestão, o crítico ponderou que o acervo do museu não era apresentado. Na época, a lista de 900 obras incluía artistas nacionais e internacionais como Picasso, Salvador Dalí, Paul Klee, Miró, Giacometti e Henry Moore.

Só há pouco tempo a importante coleção começou a ser apresentada em verdadeiro regime de rotatividade. A maior parte dela vivia estocada nos porões e, segundo dizem, com algumas peças bastante avariadas, já que o museu não tem condições de fazer a sua restauração. O problema, como se vê, é dos mais graves, e é por isso que a diretoria do MAM resolveu adotar medidas urgentes para sanear a situação. [...] A mostra Arte Brasileira - Acervo do MAM conta com 96 artistas que tiveram seus nomes selecionados por uma misteriosa Comissão de Planejamento Cultural que, segundo algumas informações, parece que já foi dissolvida por falta de concordância entre seus membros. A intenção do museu é renovar sua coleção brasileira, seja no sentido de preencher ausências, com obras de artistas representativos que lá ainda não constam, ou no de sua atualização, no caso daqueles já documentados (BITTENCOURT, 2016, p.105).

\section{Considerações finais}

Em 1982, o crítico Francisco Bittencourt, no texto Dez anos de Experimentação ${ }^{8}$ revelou uma análise retrospectiva sobre um passado recente, destacando o papel do MAM Rio na produção da vanguarda artística brasileira nos anos 1970:

8 A comunicação foi apresentada no I Encontro Nacional de Crítica de Arte, realizado em Curitiba (Paraná), em 1980. Uma versão anterior deste texto foi publicada na Revista de Cultura Vozes (Petrópolis), n. 5, ano 72, junho-julho de 1978, sob o título de A Vanguarda Visual Carioca dos Anos 70. Posteriormente, o texto foi publicado também na Revista Crítica de Arte, n.4, dezembro de 1981. Foi republicado com cortes no catálogo da exposição Depoimento de uma Geração: 1969-1970, realizada na Galeria de Arte Banerj (RJ), em julho de 1986, com curadoria de Frederico Morais. A versão com cortes foi novamente publicada nos livros Crítica de Arte no Brasil: Temáticas Contemporâneas (2006) e Arte Contemporáneo Brasileño: Documentos y Críticas (2009), ambos organizados por Glória Ferreira. 
O MAM tornou-se naturalmente centro de onde evoluíam os momentos mais avançados da arte brasileira. Em 1971, Frederico Morais tentou dar ao museu a espinha dorsal ideológica que lhe faltava, criando ali com Luiz Alphonsus e Cildo Meireles uma Unidade Experimental. Nesse mesmo ano, o crítico lançou o projeto Domingos da Criação, com grande êxito público. Os Domingos retomaram a ideia de arte no Aterro, da década passada, da promoção cultural em massa. Seguiram uma linha muito criativa e ampla e conseguiram despertar em muita gente o prazer pela forma lúdica da arte (BITTENCOURT, 2016, p.487).

Alguns anos depois, em 1986, Frederico Morais publicou o catálogo Depoimento de uma Geração 1969-1970, na ocasião do projeto Ciclo de Exposições sobre Arte no Rio de Janeiro, na Galeria Banerj, no Rio de Janeiro. A publicação trouxe textos críticos, depoimentos de artistas e imagens sobre a produção daquela virada de década. Em entrevista, a artista Thereza Simões apresenta o modo de trabalho, pesquisa e organização em torno do experimentalismo.

Na verdade, não era um grupo porque éramos muito individualistas, mas havia alguma coisa em comum entre nós, uma posição desafiadora no trabalho. Um trabalho de risco, irreverência política, uma posição muito livre em relação à arte e ao mercado (SIMÕES, 1986, não paginado).

Em 2001, o núcleo denominado como experimentalismo, que constituiu uma parte das Aquisições Essenciais, aponta para as experiências da Área Experimental e da Unidade Experimental na trajetória do MAM Rio. Seria o cumprimento do dever histórico do museu de inserir, em seu acervo, a produção desse período da instituição e da história da arte brasileira.

Marulho é de autoria de um dos mais importantes artistas brasileiros vivos, com vida e obra profundamente ligadas ao que se chamou de experimentalismo, porém não é uma obra do período intencionado pelo discurso curatorial do MAM Rio no momento de sua aquisição. Além desta questão, o gesto de apaziguamento com o passado interrompido abruptamente não teve continuidade diante da baixa frequência de exibição da obra para o público do museu. Tal problema ultrapassa a análise específica de Marulho, sendo sintomático das frágeis gestões dos acervos de nosso país, por motivos que vão além do orçamento.

O MAM Rio afirma, em seu estatuto de 1986 , Art. $2^{\circ}$, estar entre as suas finalidades o objetivo de formar coleções e manter exposições. São raros os museus no Brasil que possuem um plano de gestão de acervos que inclui políticas institucionais de aquisição e de descarte definidas e aplicadas bem como gestão de risco, planejamento e regras transparentes que protejam seu patrimônio, conforme recomenda o Conselho Internacional 
de Museus (2009). Segundo informações disponibilizadas pelo MAM Rio, a instituição passa por um processo de reestruturação e se dedica atualmente à elaboração e implementação de um plano gestor de acervo.

De acordo com o Estatuto Brasileiro de Museus - Lei n. 11.904/2009, compete à gestão de acervo a salvaguarda das coleções, o cuidado com o bem-estar físico e de conteúdo do acervo, com a segurança a longo prazo e com o acesso público ao acervo. O museu é uma instituição sem fins lucrativos com função social, cultural e de pesquisa, que tem por objetivo realizar ações de salvaguarda, de pesquisa e de comunicação de bens culturais materiais e imateriais que integram seu acervo. Suas coleções devem ser organizadas conforme a natureza e a finalidade específica a que se destinam e sua organização estrutural e funcional deve ser baseada em métodos e técnicas específicas, visando à melhor forma de documentar, conservar, investigar, comunicar, interpretar, divulgar e expor.

Não há tempo específico para o museu retirar uma obra da reserva técnica e compartilhá-la com o público. Os motivos variam de instituição para instituição, compreendendo critérios curatoriais, técnicos e logísticos. Ficam sem resposta os motivos pelos quais uma instituição que adquire uma obra dessa importância a tenha exibido apenas duas vezes em 20 anos. Considerando que a seleção de Marulho para compor o núcleo experimental das Aquisições Essenciais foi justificada pela vinculação da trajetória de seu autor com a arte experimental, considerando a magnitude do artista Cildo Meireles, vencedor do espanhol Prêmio Velázquez, em 2008, a situação fica ainda mais grave.

A ausência de políticas institucionais firmes e independentes do fluxo de gestores e projetos curatoriais distintos é tão desafiadora quanto a falta de incentivo para os museus. O subaproveitamento do acervo compromete o museu, a obra, o artista e a história da arte do país. Em casos extremos, cogita-se até a vender peças mais relevantes do acervo, como em 1975, quando o jornalista Luis Carlos Cabral publicou a matéria $O$ jeito é vender o Picasso? no jornal Opinião, do Rio de Janeiro, com a manchete:

O Museu de Arte Moderna do Rio enfrenta mais uma séria crise financeira. Sua Diretoria pensa até em sacrificar os jardins de Burle Marx para ampliar seu lucrativo parque de estacionamento. Outros acham que de seu valioso acervo possa sair a solução (CABRAL, 1975, p. 24). 
A Cabeça cubista (1909), de Pablo Picasso, sobreviveu à diretoria e à gestão do MAM Rio na época, mas não ao incêndio ocorrido três anos depois. Já a obra No 16 (1950), de Jackson Pollock, sobreviveu ao incêndio, mas não à atual gestão do museu. Em 2019, a instituição pôs a pintura à venda na casa de leilão Phillips. Por ora, os jardins de Roberto Burle Marx seguem resistindo.

A partir da amostra ofertada pelo conjunto de entrevistas, o acervo não aparece com relevância. $O$ incêndio foi mais problemático para o grupo entrevistado de forma simbólica, pela interrupção da programação do museu e menos pela perda material, mesmo se tratando de um grupo seleto de especialistas do campo da arte.

O projeto para produção e publicação do Dossiê MAM foi iniciado dois anos após a ocorrência do incêndio. Tratava-se de uma das duas pesquisas empreendidas pelo Projeto ABC, segundo Paulo Sérgio Duarte (2010), coordenador desse setor na Funarte. A outra gerou o livro Abstracionismo Geométrico e Informal, organizado por Anna Bella Geiger e Fernando Cocchiarale. Publicado pela primeira vez em 1987, tornou-se obra de referência para estudos sobre a temática da abstração no Brasil.

À exemplo do destino deste outro projeto de pesquisa, considerando que ainda temos pouco avanço nos estudos sobre instituições em nossa história da arte, entre todas as questões problemáticas levantadas, talvez esta seja uma das mais lamentáveis, pela contribuição que poderia ter realizado para a formação de profissionais de nosso campo.

A interpretação de ocupação de uma lacuna histórica pela aquisição do núcleo experimental, especialmente da obra de Marulho, aqui tratada, apesar da irregularidade de exibição, e de produção e de apresentação de pesquisa sobre a mesma, ainda pode ser qualificada, tanto para o público especializado como para o não-especializado.

\section{Referências}

AQUINO, Adriano. Depoimento. In: Projeto Arte Brasileira Contemporânea (Projeto $A B C$ ). Arte e Instituição: Museu de Arte Moderna (MAM). Rio de Janeiro, FUNARTE/INAP, s.d. Fitas cassete (120 min). Código: FC 87. Transcrição: 49 p.

BITTENCOURT, Francisco. O Acervo do MAM. Tribuna da Imprensa, Rio de Janeiro, 28 fev. 1975. In: BITTENCOURT, Francisco. Arte-dinamite. LOPES, 
Fernanda; PREDEBON, Aristóteles Angheben (texto e org.). Rio de Janeiro: Tamanduá Arte, 2016. p.105.

BITTENCOURT, Francisco. Dez anos de experimentação. Revista Crítica de Arte, n. 4, dez.1981. In: BITTENCOURT, Francisco. Arte-dinamite. LOPES, Fernanda; PREDEBON, Aristóteles Angheben (texto e org.). Rio de Janeiro: Tamanduá Arte, 2016. p.487.

BRASIL. Estatuto dos Museus. Lei 11.904, de 14 de janeiro de 2009. Disponível em:http://www.planalto.gov.br/ccivil_03/_ato20072010/2009/lei/ I11904.htm\#: :text=10\%20Consideram\%2Dse\%20museus,t\%C3\%A9cnico\%20ou\%20de\%20qualquer\%20outra. Acesso em: 22 jun. 2021.

BRITO, Ronaldo. Depoimento. [Entrevista concedida a] Alfredo Herkenhoff e Débora Danowski. In: Projeto Arte Brasileira Contemporânea (Projeto ABC). Arte e Instituição: Museu de Arte Moderna (MAM). Rio de Janeiro, FUNARTE/ INAP, s.d. Fitas cassete (68 min). Código: FC 88. Transcrição: 15 p.

CABRAL, Luis Carlos. O jeito é vender o Picasso? Opinião, Rio de Janeiro, p.24, 4 abr. 1975.

COCCHIARALE, Fernando. Folder de divulgação da Exposição Aquisições Essenciais. Rio de Janeiro: MAM Rio, 2001.

COCCHIARALE, Fernando. MAM Rio inaugura exposição "Em Polvorosa", um panorama de suas coleções. Jornal do Brasil, 26 jul. 2016. Disponível em: https://www.jb.com.br/cultura/noticias/2016/07/26/mam-rio-inaugura-exposicao-em-polvorosa-um-panorama-de-suas-colecoes.html Acesso em: 10 jun. 2021.

COREIA DO SUL. International Council of Museums. Código de ética para museus. 2009. Disponível em:

http://icom.org.br/wpcontent/themes/colorwaytheme/pdfs/codigo\%20de\%20etica/codigo_de_etica_lusofono_iii_2009.pdf. Acesso em: 22 de jun. 2021.

COUTINHO, Wilson. Depoimento. [Entrevista concedida a] Alfredo Herkenhoff e Debora Danowski. In: Projeto Arte Brasileira Contemporânea (Projeto $A B C$ ). Arte e Instituição: Museu de Arte Moderna (MAM). Rio de Janeiro, FUNARTE/INAP, s.d. Fitas cassete (27 min). Código: FC 92. Transcrição: 09 p.

DUARTE, Paulo Sergio. Depoimento. In: REINALDIM, Ivair. Espaço Arte Brasileira Contemporânea - ABC / Funarte. Artes e Ensaios, $n^{\circ} 20$, jul. 2010. p.113-139. Disponível em: https://www.ppgav.eba.ufrj.br/publica- 
cao/arte-ensaios-20/. Acesso em: 20 abr. 2021.

GOGAN, Jessica; MORAIS, Frederico. Domingos da Criação: uma coleção poética do experimental em arte e educação. Rio de Janeiro: Instituto MESA, 2017.

GULLAR, Ferreira. Depoimento. Projeto Arte Brasileira Contemporânea (Projeto ABC). Arte e Instituição: Museu de Arte Moderna (MAM). Rio de Janeiro, FUNARTE/INAP, s.d. Código: FC 90. Transcrição: 13p.

HADDAH, Amir. Depoimento. GOGAN, Jessica; MORAIS, Frederico. Domingos da Criação: uma coleção poética do experimental em arte e educação. Rio de Janeiro: Instituto MESA, 2017.

LOPES, Fernanda. Área experimental: lugar, espaço e dimensão do experimental na arte brasileira dos anos 1970. São Paulo: Prestígio Editorial, 2013.

LUSTOSA, Heloisa. Depoimento. In: Projeto Arte Brasileira Contemporânea (Projeto $A B C$ ). Arte e Instituição: Museu de Arte Moderna (MAM). Rio de Janeiro, FUNARTE/INAP, s.d. Código: FC 86. Transcrição: 52 p.

MAM RIO inaugura exposição "Em Polvorosa”, um panorama de suas coleções. Jornal do Brasil, Rio de Janeiro, 26 jul. 2016. Disponível em: https:// www.jb.com.br/cultura/noticias/2016/07/26/mam-rio-inaugura-exposicao-em-polvorosa-um-panorama-de-suas-colecoes.html Acesso em: 12 maio 2021.

MANUEL, Antonio. [Depoimento concedido a uma das autoras]. Rio de Janeiro (ateliê do artista), 12 set. 2017. (gravação em áudio - 1h25 min.)

MEIRELES, Cildo. [Depoimento concedido a uma das autoras]. Rio de Janeiro (ateliê do artista), 05 maio 2021. Transcrição: 20 p.

MEIRELES, Cildo. Através, 1983-1989. Relatos do artista. In: Cildo Meireles. Londres: Tate Publishing, 2013. (catálogo da exposição itinerante realizada na Tate Modern, Museu d'Art Contemporani de Barcelona, The Museum of Fine Arts, Houston, Los Angeles County Museum of Art e Art Gallery of Ontario).

MORAIS, Frederico. Artes Plásticas, a crise da hora atual. Rio de Janeiro: Paz e Terra, 1975.

MORAIS, Frederico. Um laboratório de vanguarda. Diário de notícias, Rio de Janeiro, 15 out 1969. Caderno Artes Plásticas.

NETTO, Cosme Alves. Depoimento. [Entrevista concedida a] Alfredo Herkenhoff e Débora Danowski. In: Projeto Arte Brasileira Contemporâ- 
nea (Projeto $A B C$ ). Arte e Instituição: Museu de Arte Moderna (MAM). Rio de Janeiro, FUNARTE/INAP, s.d. Fitas cassete (25 min). Código: FC 89. Transcrição: 8 p.

PEQUENO, Fernanda. Artes Visuais no Rio de Janeiro em 1968: MAM, Arte no Aterro, Apocalipopótese, Lygia Pape. In: REIS, Daniel Aarão et. al. 1968: reflexos e reflexões. São Paulo: Edições Sesc São Paulo, 2018. p. $141-155$.

PIMENTEL, Wanda. [Depoimento concedido a uma das autoras]. Rio de Janeiro (casa da artista), 29 set. 2017. (gravação em áudio - 1h15 min.)

ROBERTO, Maurício. Depoimento. [Entrevista concedida a] Geraldo Carneiro. In: Projeto Arte Brasileira Contemporânea (Projeto ABC). Arte e Instituição: Museu de Arte Moderna (MAM). Rio de Janeiro, FUNARTE/INAP, s.d. Fita cassete (50 min). Código: FC 91. Transcrição: 26p.

SOBRE o MAM. Disponível em: https://mam.rio/sobre/. Acesso em: 22 jun. 2021.

SIMÕES, Thereza. Depoimentos. In: MORAIS, Frederico. Depoimento de uma geração: 1969-1970. Rio de Janeiro: Galeria de Arte BANERJ, 1986. (catálogo da exposição). 